\title{
Rancang Bangun Aplikasi Smart Training Berbasis Android Menggunakan Flutter Dengan Metode RAD
}

\author{
Layla Frida Luthfyana ${ }^{* 1}$, Eko Sediyono ${ }^{2}$ \\ ${ }^{1,2}$ Universitas Kristen Satya Wacana; Jl. Diponegoro No.52-60, Salatiga, \\ Kec. Sidorejo, Kota Salatiga, Jawa Tengah, 50711, (0298)321212 \\ ${ }^{1,2}$ Jurusan Teknik Informatika, FTI UKSW, Salatiga \\ e-mail: ${ }^{* 1672017269 @ s t u d e n t . u k s w . e d u, ~}{ }^{2}$ eko@uksw.edu
}

\begin{abstract}
Abstrak
Paper ini membahas pembuatan sistem smart training berbasis Android menggunakan Flutter untuk mengatasi masalah training pada perusahaan PB yang terhambat karena Pandemi Covid-19. Hasil presentasi sistem smart training yang dibuat menunjukan bahwa sistem ini dapat dipakai untuk mengatasi masalah tersebut.Sistem smart training yang dibuat pada penelitian ini dapat memberikan laporan data training yang sudah dilakukan,data ini dapat diakses dengan memasukkan alamat domain yang sudah dibuat dan data akan otomatis di download dalam format CSV(Comma Separated Value).Prototype sistem smart training dapat digunakan untuk menggantikan sistem lama yang dinilai kurang efektif seperti, panggilan telepon kepada karyawan yang harus mengikuti training hal itu digantikan dengan fitur Firebase cloud messaging yang akan mengirimkan notifikasi ke aplikasi user jika user dijadwalkan untuk mengikuti training.Sistem smart training sudah diuji menggunakan usability testing yang menunjukan angka \% Kepuasan sebesar 80,91\% yang dikategorikan sangat baik.
\end{abstract}

Kata kunci-System Smart Training, Android, Flutter, RAD.

\begin{abstract}
This paper discusses the creation of an Android-based smart training system using Flutter to overcome the training problem on the PB companies hampered because of the Pandemic of Covid-19. The results of the presentation smart system of training that made shows that this system can be used to overcome these problems. The smart training system that is made in this study can provide data reports training that has been done, the data can be accessed by entering a domain address that is already created and the data will be automatically downloaded in CSV format(Comma Separated Value).A Prototype smart training system can be used to replace the old system which was considered less effective as, phone calls to employees who must follow the training it was replaced with the features of the Firebase cloud messaging, which will send notification to the user application if the user is scheduled to attend a training. The smart training system has been tested using usability testing that showed the numbers \% Satisfaction of $80,91 \%$, which is very well categorized.
\end{abstract}

Keywords-System Smart Training, Android, Flutter, RAD. 


\section{PENDAHULUAN}

$S$ mart training adalah aplikasi pelatihan karyawan di platform Android yang dapat diakses oleh karyawan PT.PB unit PST. Aplikasi ini digunakan untuk memberikan pelatihan kepada karyawan yang performanya kurang baik dalam bekerja, tak hanya itu aplikasi training ini juga menjadi media karyawan untuk mengenal tempatnya bekerja, aplikasi ini juga dilengkapi dengan fitur smart media untuk menggantikan mading perusahaan. Diharapkan dengan adanya aplikasi ini dapat menambah kualitas SDM di PT.PB.

PT. PB Kudus memiliki banyak bidang produksi [1]. Salah satu produk yang diunggulkan adalah smart card yang dikelola unit PST. Banyaknya permintaan dari client tentunya SDM yang unggul sangat diperlukan agar meminimalisir kegagalan produksi. Salah satu cara untuk membentuk SDM yang unggul adalah dengan diadakan training yang wajib diikuti oleh karyawan. Selama ini proses training Unit PST dimulai dari pendiskusian materi oleh divisi training, kemudian menentukan siapa saja yang akan mengikuti training dengan mempertimbangkan poin performa setiap karyawan. Setelah selesai menentukan poin-poin diatas maka, divisi training akan memanggil melalui telepon karyawan yang harus mengikuti training.

Setelah mendapatkan telepon, karyawan yang mengikuti training harus datang ke ruang training guna mengikuti training. Sebelum memulai training, peserta mengerjakan pre test agar mengetahui kemampuannya. Penyampaian materi juga masih menggunakan cara manual yang dinilai kurang efektif.

Peserta training harus mengerjakan post test yang berkaitan dengan training yang sudah disampaikan dengan mengisi lembar kertas yang disediakan. Berdasarkan masalah yang telah dijelaskan, maka latar belakang dari penelitian ini adalah membuat system smart training yang dapat digunakan untuk melakukan panggilan training, penyampaian materi training, mengerjakan pre test dan mengerjakan post test serta menjadi media baca online untuk seluruh karyawan Pura Smart Technology. Perancangan dan pembuatan aplikasi smart training ini dilakukan menggunakan metode Rapid Application Development karena metode ini mempunyai keunggulan dibanding metode konvensional lainya [2], seperti kecepatan, ketepatan serta biaya yang relatif lebih murah. Metode ini digunakan juga mempertimbangkan aplikasi smart training yang akan mengalami update fitur permintaan user kedepanya sehingga, lebih mudah di laksanakan karena metode ini mempunyai life cycle yang melibatkan user.

Framework Flutter yang dipakai untuk membangun aplikasi memungkinkan hasil dari aplikasi yang dibuat memiliki tampilan yang flexible [3]. Aplikasi dapat diakses dimanapun, karena system ini dibangun pada platform Android yang memiliki market share sebesar 71,93\% secara global [4]. Framework ini kemudian digabungkan dengan Headless CMS Strapi untuk memudahkan pengembang dalam pembuatan program dengan waktu yang cepat [5] dan Database PostgreSQL yang memiliki performa baik dan stabilitas yang tinggi [6]. Maka solusi yang diberikan untuk masalah yang ada adalah pembuatan sistem smart training yang berfungsi untuk melakukan training secara online sehingga divisi training tidak perlu melakukan panggilan telepon kepada peserta training, pengerjaan pre test, post test dan polling secara online agar mengurangi penggunaan kertas.

Terdapat beberapa penelitian yang telah dilakukan sebelumnya mengenai system Android yang akan berkaitan dengan penelitian yang sedang dilakukan. Berdasarkan sebuah penelitian yang dilakukan oleh Hakim, AR, Harefa, K dan Widodo, B berjudul "Pengembangan Sistem Informasi Akademik Berbasis Android Menggunakan Flutter Di Politeknik".Penelitian ini membahas tentang pengembangan sistem informasi akademik yang semula menggunakan powerbuilder appeon yang kemudian dikembangkan kedalam sebuah aplikasi berbasis android dengan menggunakan Flutter oleh peneliti, Hasil dari penelitian ini yaitu proses untuk mengakses sistem akademik yang dibuat menggunakan powerbuilder appeon dilakukan dengan

Luthfyana, et., al [Rancang Bangun Aplikasi Smart Training Berbasis Android Menggunakan Flutter Dengan Metode RAD] 
cara mengunduh appeon browser, setelah dibuat kedalam aplikasi android mahasiswa dimudahkan untuk mengakses informasi terbaru hanya dengan 1 aplikasi dalam smartphone mereka. Pengembangan sistem yang dilakukan dimudahkan dengan menggunakan Flutter, dimana hasil aplikasinya sangat ringan, cepat dan dapat berjalan di $i O S$ dalam satu sumber kode dan tidak membutuhkan biaya mahal seperti Power Builder [7].

Penelitian yang kedua dilakukan oleh Firmansyah, D, dengan judul "Pengembangan Front-End Aplikasi Mobile E-Recruitment Menggunakan Flutter". Penelitian ini membahas tentang pengembangan aplikasi rekrutmen online yang ditujukan untuk masyarakat, dikembangkan ke dalam aplikasi mobile karena diharapkan dapat menjangkau masyarakat lebih luas mengingat tingginya penggunaan smartphone di Indonesia. Hasil dari penelitian ini yaitu aplikasi mobile e-recruitment telah diuji dan mendapatkan persentase sebesar $70 \%$ untuk mempermudah pengguna mencari pekerjaan, ditambah lagi dalam pengembangannya peneliti menggunakan Flutter untuk membangun front-end -aplikasi. Flutter dinilai efisien dalam pengembanganya dan satu baris kode dapat di compile dalam multiplatform Android dan iOS [8].

Dari hasil dua penelitian sebelumnya penulis tertarik menggunakan Flutter untuk pembuatan aplikasi Smart Training yang dinilai mudah dalam pengembanganya, aplikasi yang dihasilkan ringan, cepat dan dapat di compile ke dalam platform Android maupun iOS. Dipadukan dengan penyimpanan data menggunakan database PostgreSQL dan membuat Realtime notification menggunakan Firebase cloud messaging.

Berdasarkan latar belakang yang telah dijelaskan, didapatkan rumusan masalah yaitu bagaimana membuat sistem smart training yang dapat memberikan kemudahan dalam pelaksanaan training serta membuat pelaksanaan training menjadi lebih efisien. Batasanbatasan dalam pembuatan sistem smart training diantaranya, system smart training akan dibuat pada perangkat Android menggunakan Flutter dengan Bahasa pemrograman Dart dengan menggunakan PostgreSQL sebagai database dan menggunakan Headless CMS Strapi untuk pengisian konten, system yang dibuat memerlukan minimal versi API 23 dan target versi API 29.

\section{METODE PENELITIAN}

Penelitian yang dilakukan menggunakan 5 tahapan penelitian yaitu: (1) analisis kebutuhan dan pengumpulan data, (2) perancangan sistem, (3) perancangan aplikasi, (4) implementasi dan pengujian sistem (5) penulisan laporan hasil penelitian [10]. Tahapan yang dilakukan dalam penelitian dapat dilihat pada Gambar 1. 


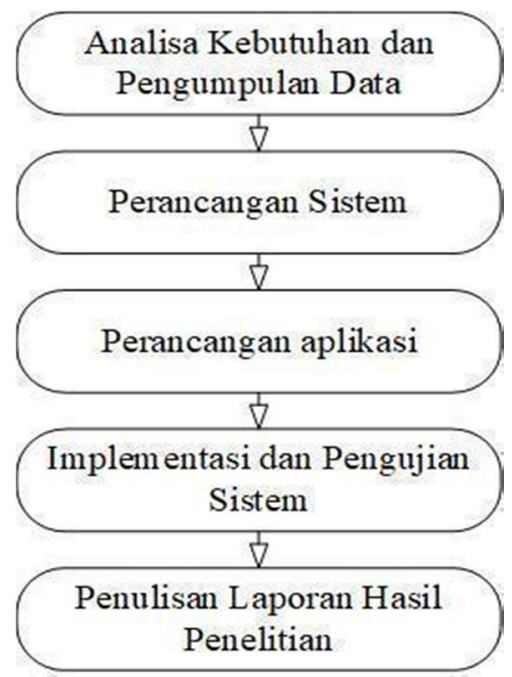

Gambar 1. Tahapan Penelitian

Berdasarkan bagan pada Gambar 1 dijelaskan bahwa tahapan penelitian yang pertama adalah Analisa kebutuhan dan pengumpulan data, di mana pihak pengembang mencari informasi mengenai kebutuhan apa saja yang dibutuhkan oleh pengguna yang berhubungan dengan aplikasi smart training. Pencarian informasi dilakukan dengan melakukan wawancara langsung kepada karyawan divisi training PT. PB Unit PST. Berdasarkan hasil wawancara yang dilakukan didapatkan informasi bahwa divisi training belum memiliki sistem yang dapat memudahkan kinerja divisi training, serta cara pelaksanaan training yang dinilai kurang efektif dan penggunaan kertas untuk mengisi pre test dan post test selama training juga dinilai boros. Informasi lain yang didapat adalah karyawan divisi training harus melakukan panggilan satu persatu kepada peserta training dengan menggunakan telepon. Divisi training meminta bantuan untuk pembuatan system smart training yang dapat menyelesaikan masalah tersebut. Pada tahap kedua dilakukan perancangan sistem smart training menggunakan metode RAD (Rapid Application Development). Tahap ketiga dilakukan perancangan aplikasi dengan menggunakan Flutter, tahap keempat implementasi sistem dan pengujian sistem yang akan dilakukan oleh karyawan yang bersangkutan, dan yang kelima dilakukan penulisan laporan ilmiah dan artikel ilmiah.

Perancangan dan pembuatan aplikasi dalam penelitian ini dilakukan menggunakan metode RAD (Rapid Application Development). Metode pengembangan perangkat lunak yang memprioritaskan rilis dan iterasi prototype cepat [9], metode ini menggunakan siklus untuk menghasilkan sebuah program. Program yang dihasilkan akan di demonstrasikan, perbaikan jika ada kekurangan, kemudian build ulang sesuai revisi, siklus tersebut diulang sampai system yang dibuat tidak mendapatkan revisi oleh user.

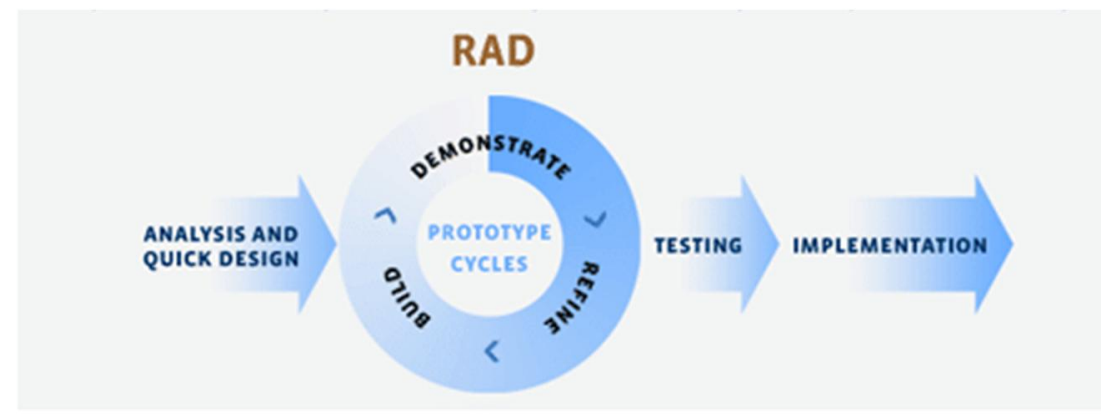

Gambar 2. Metode RAD (Rapid Application Development) [9]

Luthfyana, et., al [Rancang Bangun Aplikasi Smart Training Berbasis Android Menggunakan Flutter Dengan Metode RAD] 
Gambar 2 yang menerangkan metode RAD dimulai dengan analysis and quick design yaitu analisis dan desain cepat kebutuhan sistem untuk aplikasi yang akan dibuat. Analisa yang dilakukan dengan cara mendiskusikan dengan berbagai pihak yang bersangkutan untuk menentukan dan menyelesaikan persyaratan dan kebutuhan apa saja yang akan dipakai untuk membangun aplikasi, jika semua kebutuhan dan persyaratan jelas dan sudah menentukan setiap cakupan proyek, barulah pengembang dapat meminta persetujuan dari pihak manajemen.Langkah selanjutnya adalah building prototypes.

Build Prototype merupakan proses di mana software akan dirancang secara garis besar berjalannya aplikasi sesuai dengan data yang sudah didapat. Pembuatan desain program dibuat dengan menggunakan software bantuan (software UML). Pada tahap perancangan prototypes, data yang diperoleh sebelumnya harus dipertimbangkan dengan matang untuk menentukan fitur apa saja yang harus dibuat, rancangan prototype akan diubah menjadi bahasa pemrograman yang dijalankan oleh platform tujuan. Programmer akan menerjemahkan kebutuhan sistem yang didapat dari langkah sebelumnya. Pembuatan aplikasi smart training dalam penelitian ini menggunakan Flutter dengan bahasa pemrograman Dart guna membuat aplikasi berbasis Android.Setelah melakukan building prototypes, maka sistem akan masuk dalam tahapan demonstrate and Gather user feedback,dimana pada langkah ini prototype dan system yang telah jadi, kemudian didemonstrasikan kepada user serta mengumpulkan umpan balik dari user untuk mengubah dan meningkatkan prototype agar mendapatkan aplikasi yang sesuai dengan kebutuhan, setelah mendapatkan feedback maka langkah selanjutnya adalah refine atau memperbaiki sistem yang belum sesuai dengan kebutuhan user, cycle ini akan berulang sampai prototype sesuai dengan keinginan user, langkah yang diambil setelah prototype cycle selesai adalah testing, dimana pengembang diharuskan menguji aplikasi demi kelancaran fungsinya agar dapat dinilai apakah sistem sudah siap untuk dipakai atau belum dan memastikan bahwa semua bagian sesuai dengan harapan klien. Pengujian sistem yang dibuat dilakukan dengan blackbox testing [11]. Saat sistem sudah dinyatakan lulus tahapan testing, maka system sudah siap untuk masuk ke dalam tahap implementasi yang menjadi tahap terakhir sebelum aplikasi diluncurkan.

Tahap terakhir dari penelitian ini adalah analisis dan pengambilan kesimpulan. Analisa dilakukan untuk menilai apakah algoritma yang dipakai dalam aplikasi sudah baik atau malah sebaliknya. Analisa kebutuhan perangkat keras dan spesifikasi perangkat lunak yang digunakan dalam membangun jurnal ini yaitu: Perangkat keras yang digunakan adalah Processor AMD Ryzen 5 @3.70 GHz, RAM 8 GB. Perangkat lunak yang digunakan adalah OS Windows 10, Visual Studio Code 1.52.1 dan StarUML untuk membuat diagram UML.

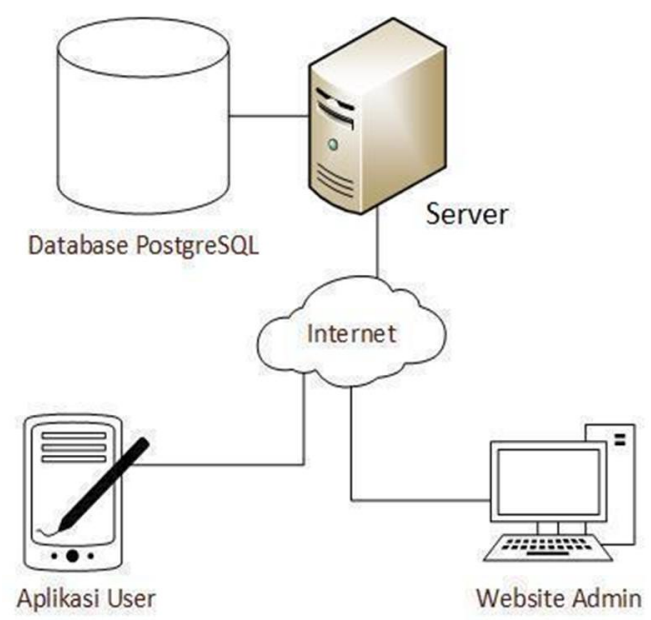

Gambar 3. Desain Arsitektur Sistem 
Gambar 3 menjelaskan desain arsitektur sistem yang dibuat. System smart training dirancang menggunakan 1 server dengan IP publik yang digunakan sebagai server Database PostgreSQL dan web API serta perangkat Android milik user yang terinstal aplikasi smart training dan komputer untuk mengakses Headless CMS Strapi.Perancangan sistem dibuat dalam bentuk diagram UML. Diagram UML meliputi use case diagram dan class diagram.

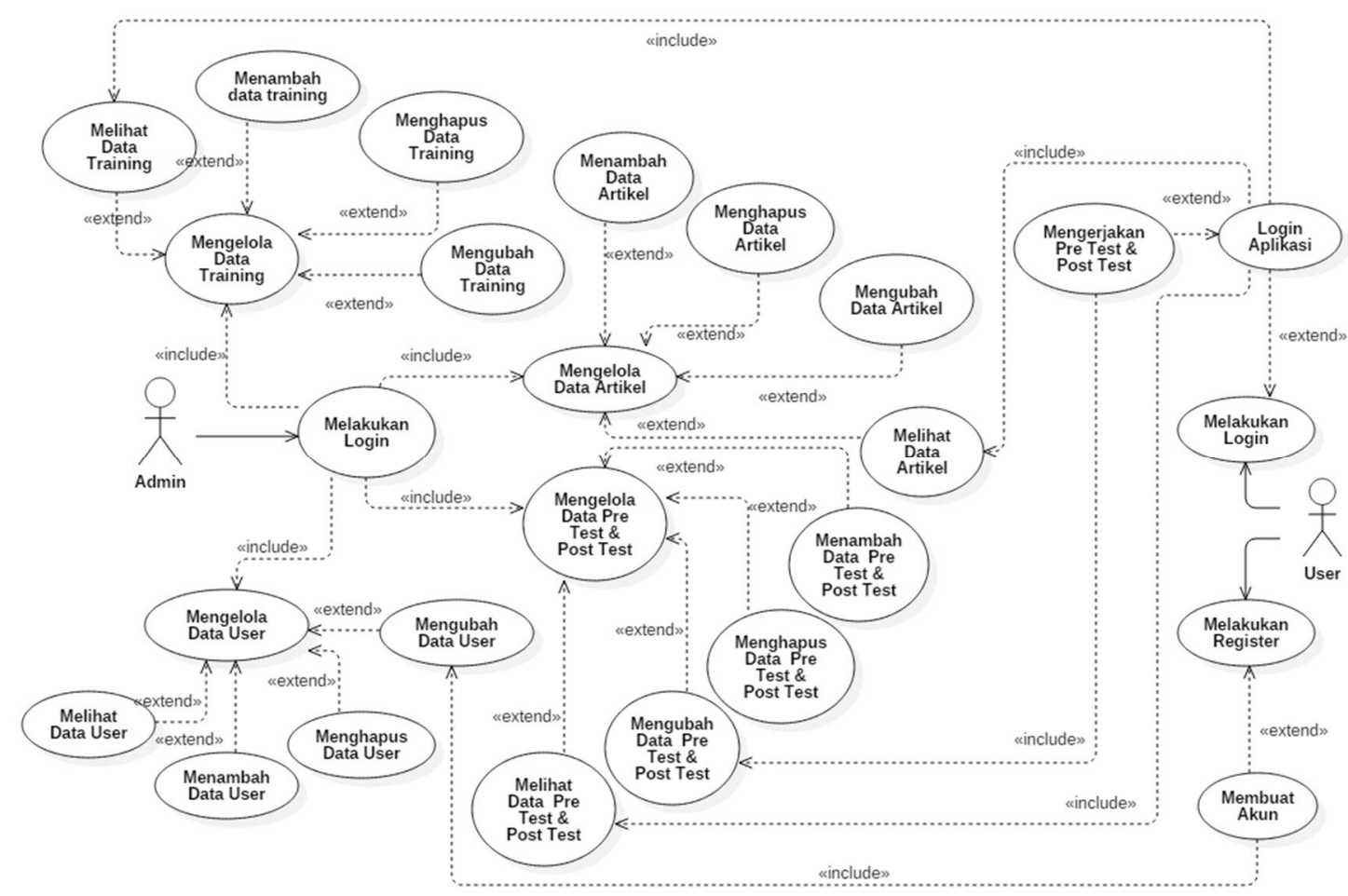

Gambar 4 Use Case Diagram Aplikasi Smart Training

Gambar 4 merupakan use case yang menerangkan bagaimana aplikasi smart training dibuat. Aplikasi ini mempunyai dua aktor utama yaitu admin yang mempunyai akses penuh untuk mengelola konten dan monitoring training user serta mengolah data report training setiap user. Kedua adalah user, user memiliki hak akses untuk melakukan login ke dalam aplikasi jika akun yang user buat sudah diaktifkan oleh admin, user dibedakan menjadi dua yaitu, user office dan user borong, Di masing-masing akun mempunyai konten yang berbeda menyesuaikan akun apa yang dipakai untuk login. 


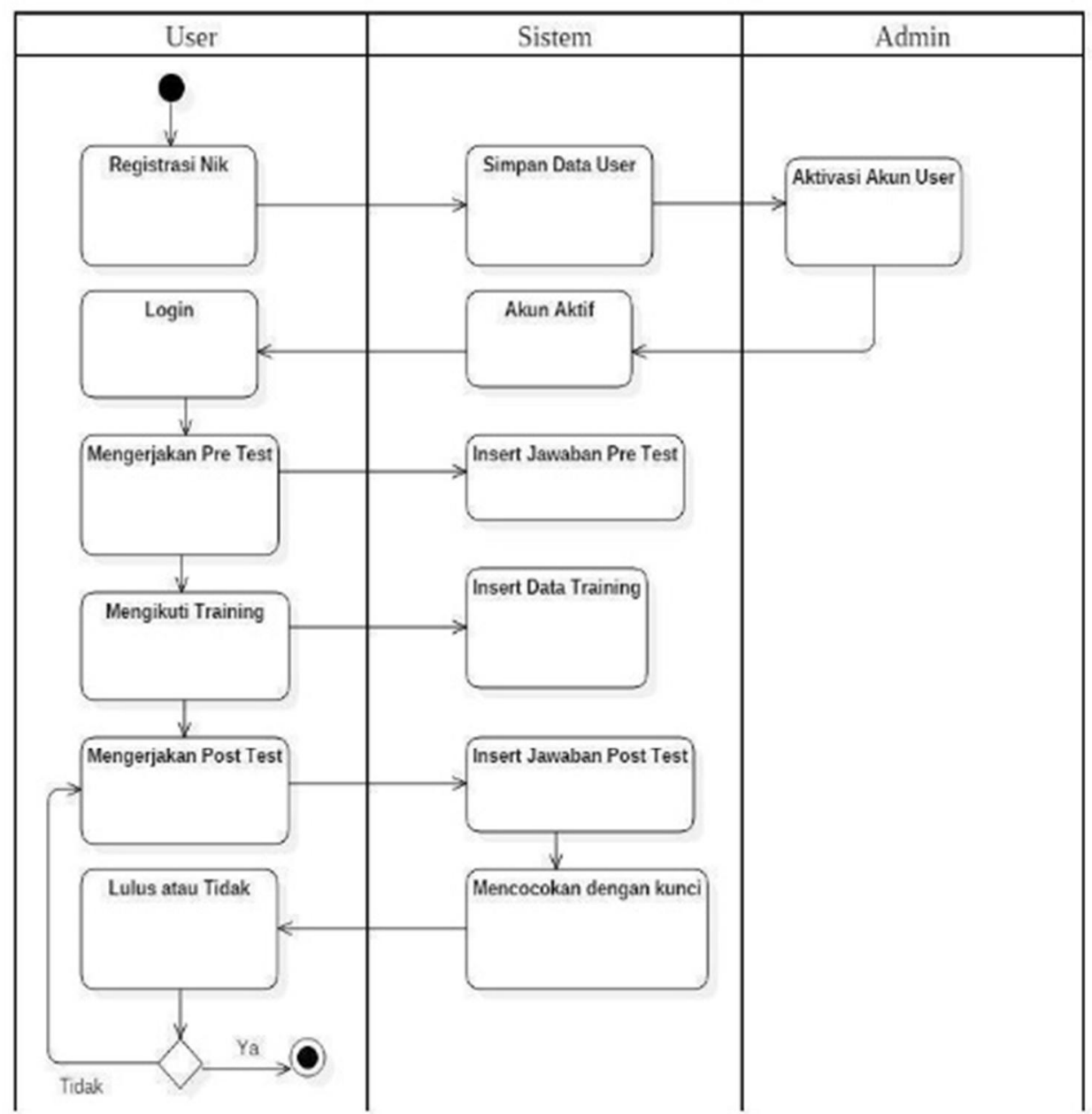

Gambar 5. Activity Diagram Melakukan Training

Gambar 5 merupakan activity diagram yang menggambarkan login user dan garis besar pelaksanaan training serta pengerjaan pre test dan post test. Sebelum user dapat mengakses aplikasi, user harus memiliki akun yang sudah diaktifkan oleh admin, akun bisa didapat dengan cara mendaftarkan NIK (nomor induk karyawan) yang masih terdaftar di perusahaan. Setelah akun aktif, user dapat mengakses informasi yang terdapat di dalam aplikasi termasuk data training. Sebelum bisa mengikuti training, user harus mengerjakan pre test yang disediakan dan user bisa mengikuti training yang dipilih. Setelah selesai, user akan diarahkan ke halaman post test guna mengetahui seberapa jauh pemahaman user terhadap training yang baru saja diikuti. Ketika user menekan tombol submit, jawaban akan masuk ke database dan total nilai dari post test yang dikerjakan akan muncul beserta keterangan lulus atau tidaknya peserta mengikuti training tersebut, jika belum lulus peserta diberi kesempatan satu kali mengerjakan post test ulang. 


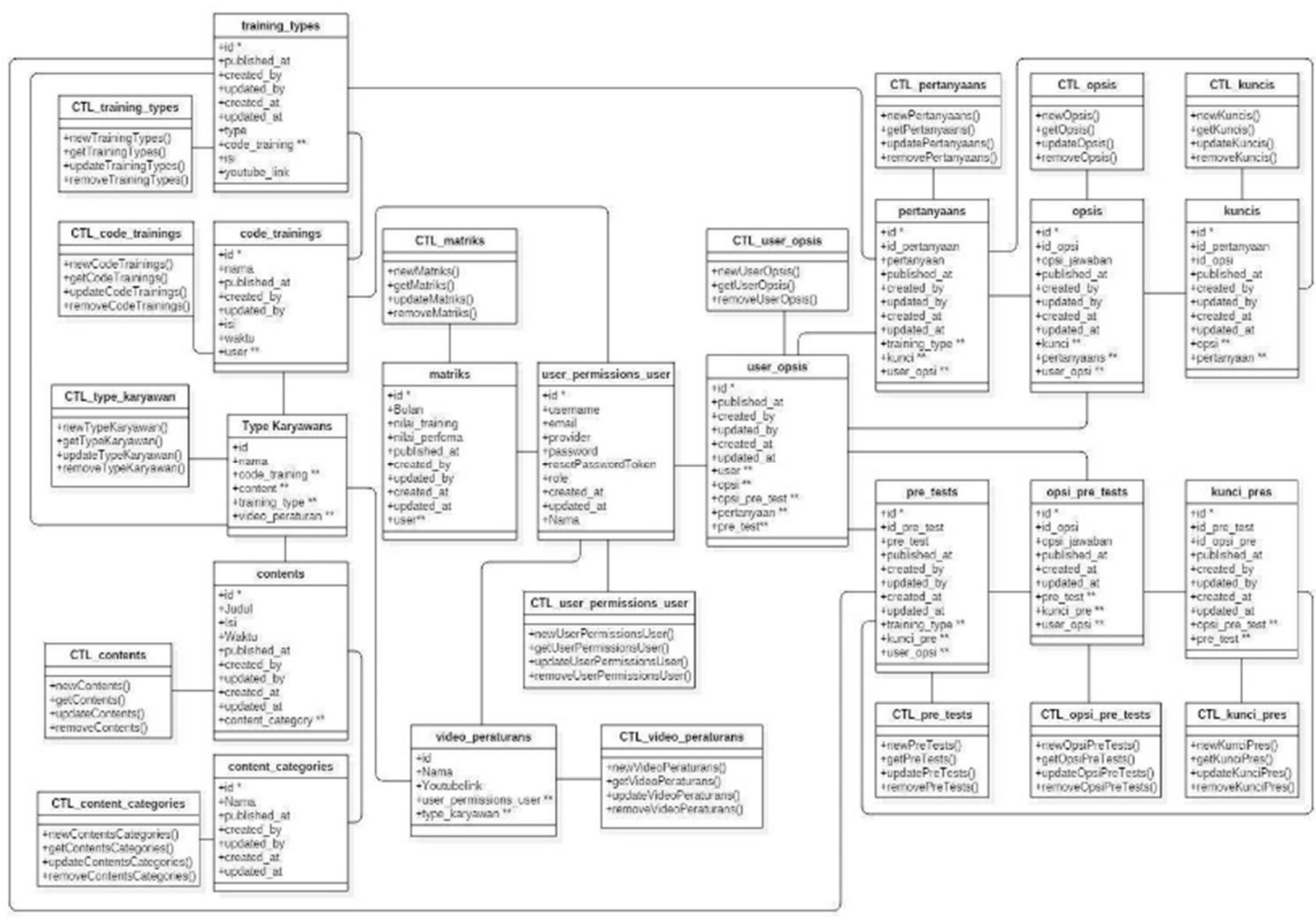

Gambar 6. Class Diagram Aplikasi Smart Training

Gambar 6 menunjukkan class diagram dari sistem Smart Training yang dibuat. Terdapat total 15 class yang digunakan untuk mengakomodasi kebutuhan sistem Smart Training, meliputi artikel, konten training, hingga penilaian yang digunakan untuk mengevaluasi kemampuan karyawan sebelum dan sesudah training. Terdapat class type karyawan yang digunakan untuk memisahkan konten antar user borong dan user office.

Sistem smart training dievaluasi dengan cara trial aplikasi yang melibatkan kepala bagian staff borong dan office selama satu minggu, evaluasi ini dilakukan dengan maksud menguji algoritma berjalanya aplikasi smart training. Hal ini perlu dilakukan mengingat aplikasi harus berjalan tanpa adanya error dengan mempertimbangkan segala jenis kondisi. Evaluasi selanjutnya adalah dengan cara simulasi proses bisnis yang dilakukan di Unit Pura Smart Technology untuk mencocokan apakah proses bisnis yang diimplementasikan sudah sesuai dengan kemauan user atau perlu perbaikan. Selama pembuatan sistem, dilakukan beberapa penambahan dan perbaikan pada proses bisnis seperti yang tertulis pada Tabel 1.

Tabel 1. Evaluasi Proses Bisnis

\begin{tabular}{|c|l|l|l|l|}
\hline $\begin{array}{c}\text { Evaluasi } \\
\text { ke- }\end{array}$ & \multicolumn{1}{|c|}{$\begin{array}{c}\text { Bagian } \\
\text { Evaluasi }\end{array}$} & $\begin{array}{l}\text { Kondisi Sebelum } \\
\text { Evaluasi }\end{array}$ & \multicolumn{1}{|c|}{$\begin{array}{c}\text { Kondisi Setelah } \\
\text { Evaluasi }\end{array}$} & Alasan Perbaikan \\
\hline 1 & $\begin{array}{l}\text { Algoritma } \\
\text { Login }\end{array}$ & $\begin{array}{l}\text { Setiap orang yang } \\
\text { melakukan } \\
\text { registrasi bs } \\
\text { langsung login }\end{array}$ & $\begin{array}{l}\text { Setelah daftar } \text { user } \\
\text { menunggu akun } \\
\text { diaktivasi oleh } \\
\text { admin, baru } \text { user } \text { bisa } \\
\text { login. }\end{array}$ & $\begin{array}{l}\text { Orang diluar } \\
\text { perusahaan dapat } \\
\text { mendaftar dengan } \\
\text { sembarang NIK }\end{array}$ \\
\hline 2 & $\begin{array}{l}\text { Fitur } \\
\text { Training }\end{array}$ & $\begin{array}{l}\text { Setiap peserta } \\
\text { langsung } \\
\text { mengikuti } \\
\text { training }\end{array}$ & $\begin{array}{l}\text { Sebelum mengikuti } \\
\text { training peserta wajib } \\
\text { mengisi pre test. }\end{array}$ & $\begin{array}{l}\text { Kesulitan untuk } \\
\text { menentukan } \\
\text { kemajuan peserta } \\
\text { training }\end{array}$ \\
\hline
\end{tabular}

Luthfyana, et., al [Rancang Bangun Aplikasi Smart Training Berbasis Android Menggunakan Flutter Dengan 


\begin{tabular}{|c|l|l|l|l|}
\hline & & & \\
\hline 3 & $\begin{array}{l}\text { Perhitungan } \\
\text { nilai pada } \\
\text { pre test } \text { dan } \\
\text { post test }\end{array}$ & $\begin{array}{l}\text { Nilai akan keluar } \\
\text { setiap pre test dan } \\
\text { post test } \text { selesai }\end{array}$ & $\begin{array}{l}\text { Hitungan nilai hanya } \\
\text { diletakan pada post } \\
\text { test }\end{array}$ & $\begin{array}{l}\text { Peserta akan merasa } \\
\text { putus asa jika hasil } \\
\text { tidak sesuai. }\end{array}$ \\
\hline 4 & $\begin{array}{l}\text { Screen } \\
\text { security }\end{array}$ & $\begin{array}{l}\text { Peserta bisa } \\
\text { melakukan } \\
\text { screenshot dan } \\
\text { screen recording } \\
\text { pada aplikasi }\end{array}$ & $\begin{array}{l}\text { Penambahan screen } \\
\text { security }\end{array}$ & $\begin{array}{l}\text { Terdapat data2 yang } \\
\text { tidak boleh diketahui } \\
\text { pihak luar }\end{array}$ \\
\hline 5 & Training & $\begin{array}{l}\text { Tidak ada } \\
\text { notifikasi jika } \\
\text { training baru } \\
\text { ditambahkan }\end{array}$ & $\begin{array}{l}\text { Penambahan } \\
\text { notifikasi pada } \\
\text { aplikasi jika training } \\
\text { ditambahkan atau } \\
\text { diubah }\end{array}$ & $\begin{array}{l}\text { Untuk penanda } \\
\text { training baru yang } \\
\text { ditambahkan }\end{array}$ \\
\hline
\end{tabular}

\section{HASIL DAN PEMBAHASAN}

Dalam penelitian ini Sistem smart training terdiri dari 1 aplikasi berbasis Android dan 1 Headless CMS Strapi. Aplikasi Android digunakan oleh user untuk mengakses informasi tentang training yang diselenggarakan, pre test dan post test serta artikel terkait dengan perusahaan. Sedangkan Headless CMS Strapi untuk admin digunakan oleh administrator mengelola konten yang akan ditampilkan di dalam aplikasi user. Garis besar berjalannya aplikasi smart training adalah sebagai berikut: (1) User membuka aplikasi, jika memiliki akun yg sudah diaktifkan oleh admin, user bisa langsung login ke dalam aplikasi, jika belum user harus mendaftarkan NIK/ Id borong di halaman registrasi kemudian menunggu admin untuk mengaktifkan akun. (2) User masuk ke halaman profil guna melihat training yang wajib diikuti atau masuk ke halaman training untuk melihat keseluruhan training yang tersedia. (3) Ketika di halaman profil terdapat training yang direkomendasikan oleh admin untuk user, maka user wajib mengikut training tersebut, dengan cara memilih training serta sesi training yang akan diikuti dan user akan diarahkan ke halaman pre test. (4) User mengikuti training setelah mengerjakan pre test. (5) User mengerjakan post test setelah training selesai dan informasi nilai serta status kelulusan akan muncul setelah post test selesai, jika tidak lulus user diberi satu kali kesempatan untuk mengikuti post test ulang. 

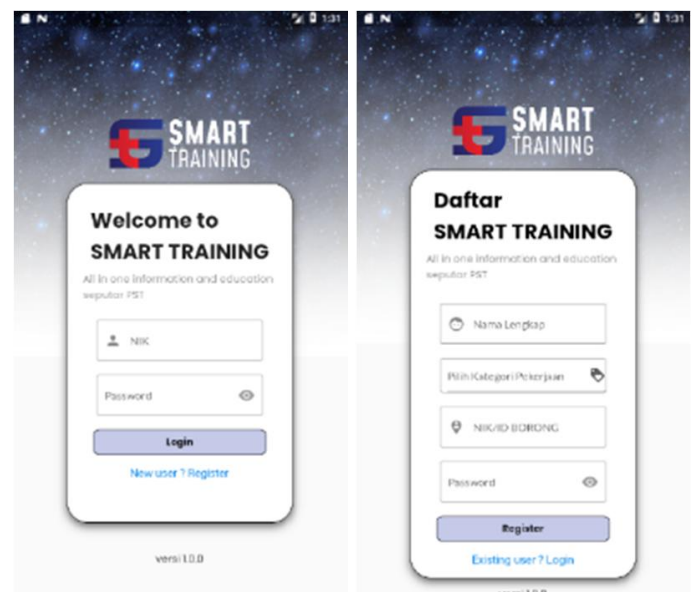

Gambar 7. Halaman Login \& Register App Smart Training

Sistem smart training dimulai dengan user melakukan login menggunakan akun yang sudah diaktifkan oleh admin. Untuk melakukan login, perangkat Android user harus terkoneksi ke jaringan seluler, nik dan password yang dimasukkan akan dicocokan dengan data yang ada di database. Jika belum mempunyai akun maka, user harus mendaftarkan Nik/Id borong di halaman registrasi, kemudian menunggu admin mengaktifkan akun. Setelah menekan tombol login seperti yang digambarkan pada Gambar 4. Mekanisme login ini melalui beberapa proses: (1) cek akun user sudah diaktifkan atau belum. (2) jika sudah diaktifkan sistem menyimpan data user login untuk mengambil data dalam database dan menentukan akun tersebut menampilkan konten untuk user office atau user borong. Kode Program 1 menunjukan source code untuk cek akun sudah diaktifkan atau belum.

$$
\begin{aligned}
& \text { 1.final responseData }=\text { json.decode }(\text { response.body); } \\
& \text { 2.if (response.statusCode }==200)\{ \\
& \text { 3.final bool isUserActive }=\text { responseData['user']['active']; } \\
& \text { 4.if (isUserActive }==\text { null } \| \text { !isUserActive) }\{
\end{aligned}
$$

\section{Gambar 8. Kode Program Metode Cek Akun User Diaktivasi}

Jika status berhasil, maka aplikasi akan mengecek akun yang dimasukan sudah diaktifkan atau belum. Jika sudah diaktifkan di dalam kolom database user akan muncul keterangan active dan jika belum maka akan berisi null, di dalam aplikasi juga diberi kondisi seperti, jika akun masih berstatus null maka akan muncul pop up dialog berisi keterangan akun anda belum diaktifkan.

\section{1.void getUser() async \{}

2. try \{

3. //menyimpan user login

4. SharedPreferences sharedPreferences $=$

5. await SharedPreferences.getInstance();

6. sharedPreferences.setString('identifier', _usernameCtl.text);

7. final user $=$ await service.getUser();

8. sharedPreferences.setInt(

9. 'typeKaryawan', user.type karyawan.id); //menyimpan type user login

10. sharedPreferences.setInt('idUser', user.id);

Gambar 9. Kode Program Functions Menyimpan Data User Login 
Pengambilan data dari dalam database untuk ditampilkan di dalam aplikasi menggunakan metode SharedPreferences dimana, nomor induk karyawan yang dimasukan saat login berhasil, akan disimpan didalam SharedPreferences kemudian akan dicocokan dengan data yang ada di database. Di dalam SharedPreferences juga menyimpan id type karyawan login guna menentukan konten apa yang akan user lihat di dalam aplikasi. Pasalnya aplikasi ini dapat melakukan login dengan multi user (office dan borong) dengan konten yang berbeda antara dua user tersebut.
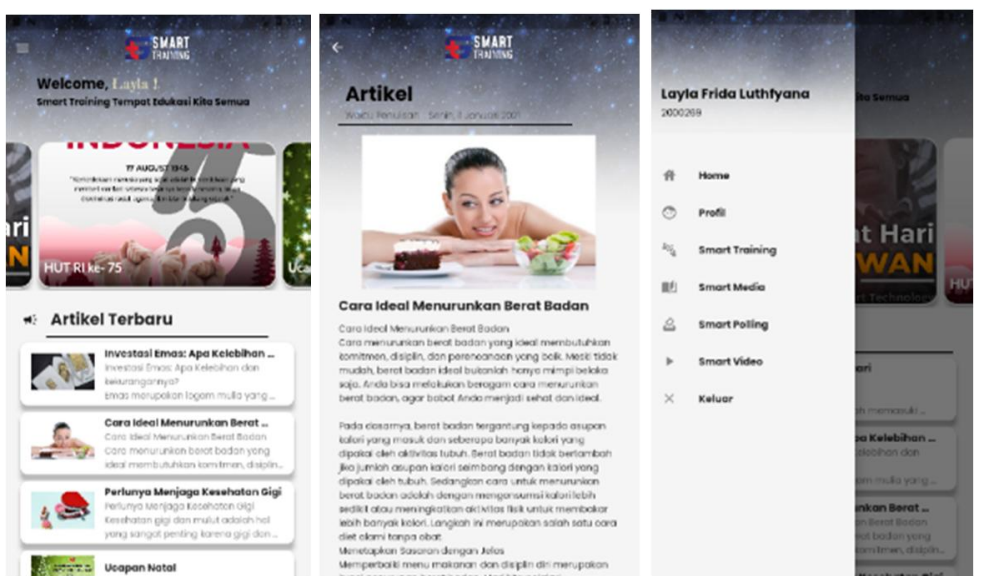

Gambar 10. Halaman Utama Aplikasi, Detail Artikel, dan Menu Utama

Fitur lain yang terdapat didalam aplikasi smart training adalah adanya fitur smart media, dimana user dapat melihat pengumuman, membaca artikel seputar perusahaan maupun artikel dari sumber lain. Maksud dari penambahan fitur smart media ini diharapkan dapat membangun minat baca user, serta aplikasi dapat digunakan dengan semaksimal mungkin. Terdapat 6 menu dalam halaman utama aplikasi smart training yang dapat dilihat pada Gambar 10, menu dari atas ke bawah adalah: (1) menu home, (2) menu profil, (3) menu training, (4) menu smart media, (5) menu smart polling, (6) menu smart video (akun user borong).
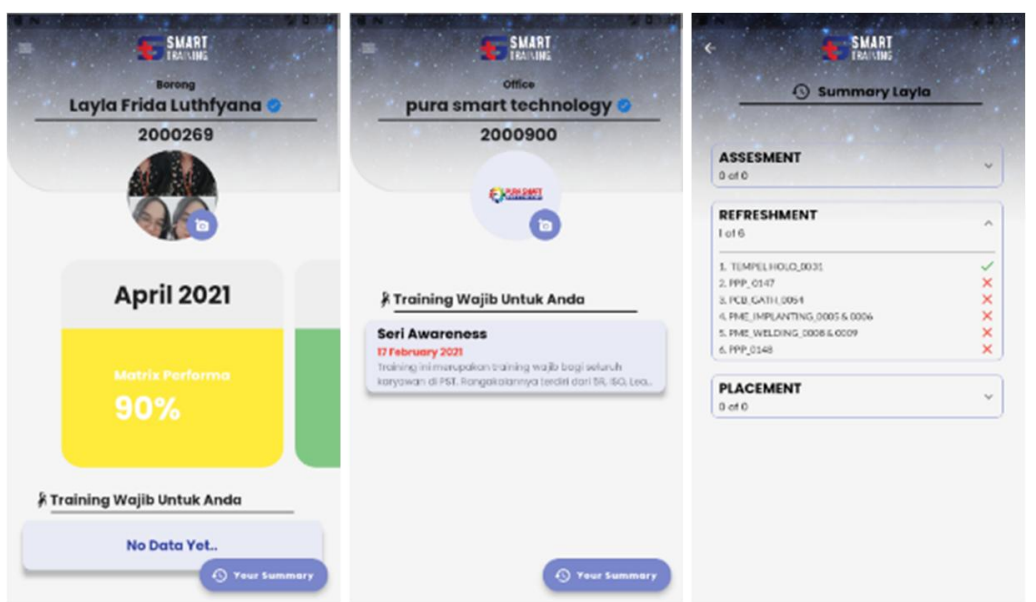

Gambar 11. Halaman Profil User Office, User Borong dan Summary Report

Gambar 11 menunjukan menu profil yang digunakan user untuk melihat informasi tentang dirinya. Fitur profil di dalam akun borong akan menampilkan informasi pribadi yang user masukan saat melakukan registrasi akun, matriks performa selama 5 bulan terakhir yang berisikan nilai performa user. Ketentuan warna dalam matriks performa sebagai berikut: (1).

Luthfyana, et., al [Rancang Bangun Aplikasi Smart Training Berbasis Android Menggunakan Flutter Dengan Metode RAD] 
Jika nilai user dibawah 70 matriks akan berwarna abu-abu, (2). Jika diatas 70 matriks akan berwarna merah, (3). Jika dibawah 90 matriks akan berwarna kuning, (4) Dan diatas 100 matriks berwarna hijau. Selanjutnya training wajib yang direkomendasikan oleh admin dan wajib diikuti oleh user tersebut, terakhir adalah summary report berisi training yang tersedia dan keterangan user login sudah mengikuti setiap sesi dalam training. Hal itu disimbolkan dengan centang hijau yang berarti sudah mengikuti serta tanda silang merah jika user belum mengikuti sesi training. Sedangkan fitur profil dalam akun office tidak terdapat matriks performa. Nilai performa hanya dimiliki oleh user borong.
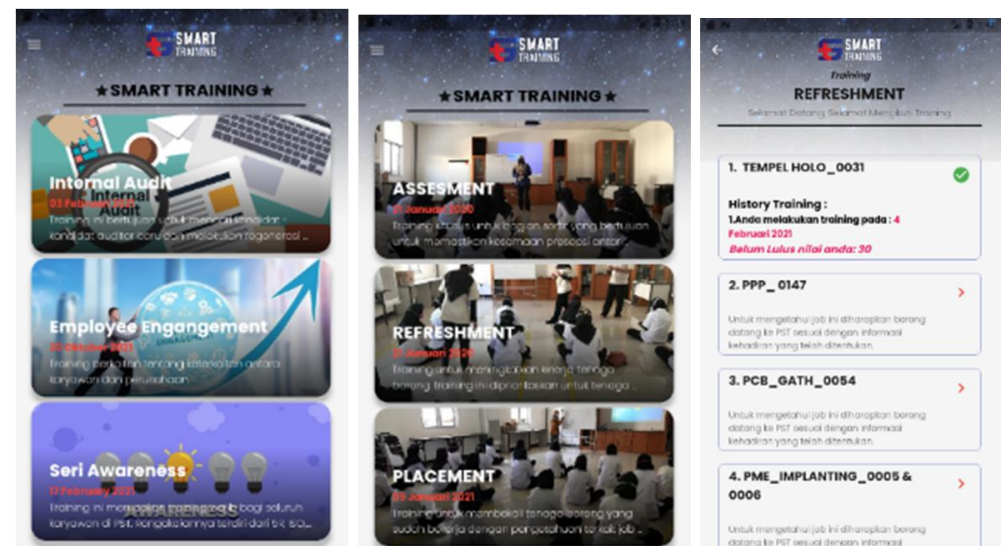

Gambar 12. Menu Training Untuk User Office \& Borong Serta Sesi Pelaksanaan Training

Gambar 12 menunjukan training yang tersedia untuk user. User office dan user borong memiliki jenis training yang berbeda. Disetiap training memiliki sesi training dan di dalam sesi training terdapat pre test dan post test. Di halaman sesi training, user dapat melihat sesi yang sudah dan belum diikuti. Sesi training yang sudah diikuti akan mempunyai history training serta tanda centang hijau pada pojok kanan atas. History ini diambil dengan mencocokan data submit post test user dengan kode training yang terdapat dalam sesi training.

Kemudian User memilih training yang belum diikuti dan diarahkan ke halaman pre test untuk melihat pemahaman user terhadap training yang akan diikuti, user akan diberi waktu selama 10 menit untuk mengerjakan soal, jika user tidak dapat mengerjakan semua soal selama waktu yang sudah ditentukan, jawaban akan otomatis di submit ke dalam database. Gambar 13 menunjukan functions submit untuk banyak jawaban dalam pre test dan post test.

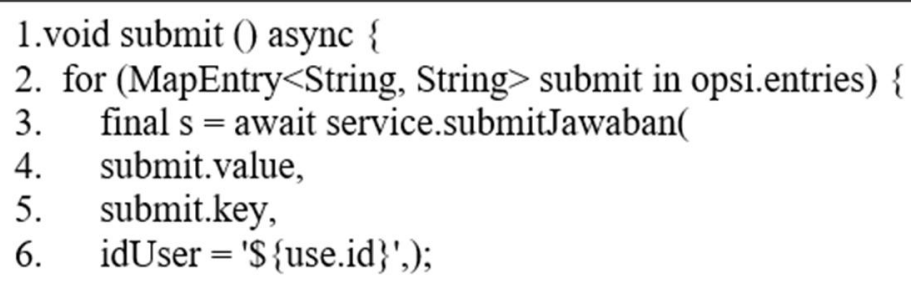

\section{Gambar 13. Kode Program Metode Submit Banyak Jawaban}

Jika user menekan tombol submit, maka jawaban akan dimasukan ke dalam database sesuai banyak soal yang user kerjakan. Sistem akan mengirimkan id soal, id opsi, serta id user ke dalam database, data yang dikirim kemudian akan digunakan untuk mencocokan jawaban user dengan kunci jawaban yang telah dibuat oleh admin. Setelah dicocokan, hasil akan muncul saat user selesai mengerjakan post test. Halaman post test dapat dilihat pada Gambar 14. 

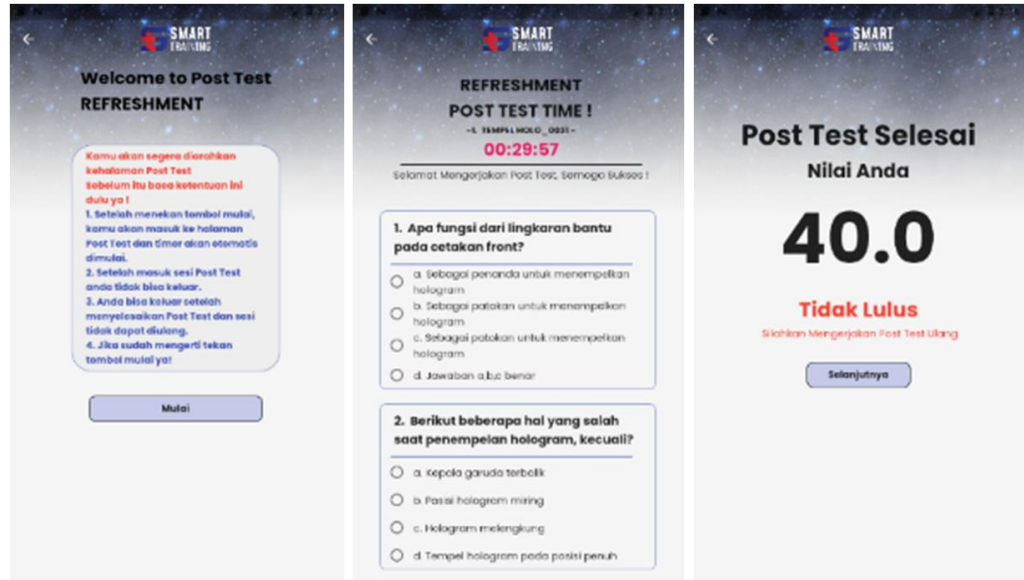

Gambar 14. Penjelasan Post Test, Halaman Post Test dan Skor Akhir Post Test

Gambar 14 menunjukan halaman penjelasan yang berisi ketentuan pengerjaan post test. Setelah menekan tombol mulai timer di dalam post test akan otomatis dimulai dan user bisa mulai mengerjakan soal yang tersedia selama waktu yang diberikan. Berbeda dengan pre test, user dapat melihat hasil yang didapatkan selama mengerja kan post test. Skor ini yang akan menentukan kelulusan user pada sebuah training, jika user tidak lulus maka diberikan 1 kali kesempatan untuk mengikuti post test ulang.

1.double_hitungNilai(int trainingTypeId) \{

...

8. $\quad$ double poin $=0$;

9. for (var answer in answers) \{

10. int indexPertanyaanlistKunciQuiz.indexOf(listKunciQuiz.firstWhere(

11. $\quad$ (element) $=>$ element.idPertanyaan $==$ answer.pertanyaan.idPertanyaan));

12. if (listKunciQuiz[indexPertanyaan].idOpsi $==$ answer.opsi.idOpsi) \{

13. $\quad$ poin $+=1$;

Gambar 15. Kode Program Pencocokan Jawaban dengan Kunci Jawaban

Fungsi pada Gambar 15 berguna untuk mencocokan nilai pada pre test dan post test dalam setiap sesi training. Selain menginput soal, admin juga memasukan kunci jawaban. Fungsi ini nanti sangat berpengaruh untuk status kelulusan user dalam mengikuti training.

User akan di berikan waktu untuk menyelesaikan soal test barulah admin bisa mengambil data skor user dengan memasukan link http://192.168.5.254:8000/report dan perangkat terkoneksi Wi-Fi Perusahaan, otomatis data akan terdownload dengan format CSV. Proses akan digambarkan di bawah ini.

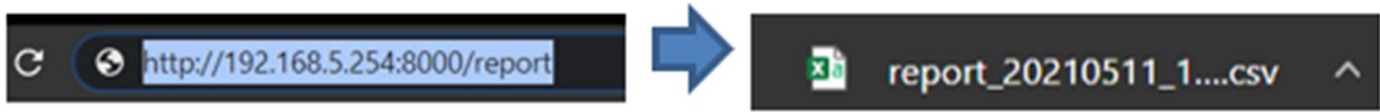

Gambar 16. Proses Download File .CSV

File CSV akan ter-download dan masuk pada folder download perangkat, setelah itu file bisa dibukan melalui aplikasi excel dengan cara masuk ke halaman baru dan masuk ke menu data dan pilih from text /CSV dan data skor sudah bisa dilihat.

Luthfyana, et., al [Rancang Bangun Aplikasi Smart Training Berbasis Android Menggunakan Flutter Dengan Metode RAD] 

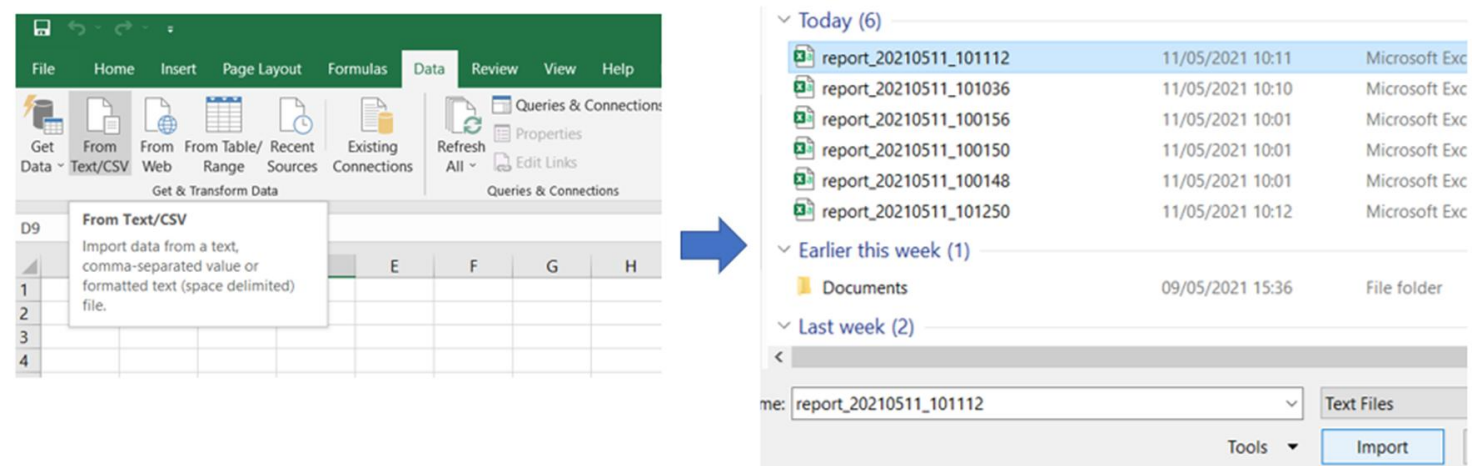

Gambar 17. Proses Import File .CSV

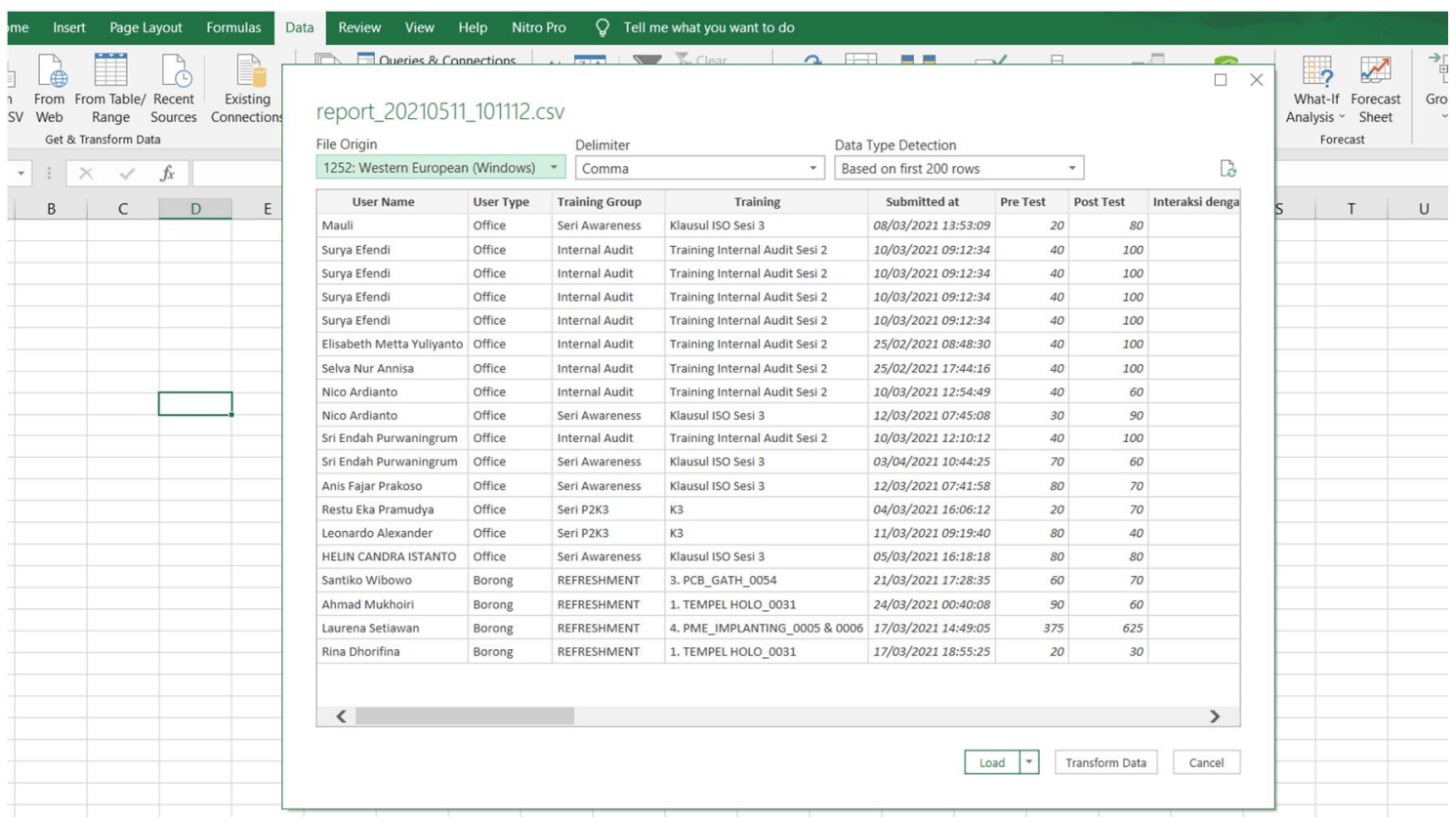

Gambar 18. Data Hasil Skor yang Didapat Oleh User

Pengujian sistem dilakukan untuk menguji fungsi yang telah dibuat dalam prototype sistem smart training. Pengujian sistem dilakukan menggunakan metode usability testing. Usability Testing dilakukan untuk mengetahui apakah sistem telah memenuhi kebutuhan yang ada di dalam aplikasi smart training (System Usability). Hasil usability testing pada sistem ini diketahui dengan menggunakan kuesioner berisi pertanyaan positif [12] yang terdapat pada Tabel 2.

Tabel 2. Daftar Pertanyaan Usability Testing

\begin{tabular}{|c|l|c|c|c|c|c|}
\hline No & \multicolumn{1}{|c|}{ Daftar Pertanyaan } & \multicolumn{5}{|c|}{ Penilaian } \\
\hline 1 & $\begin{array}{l}\text { Secara Keseluruhan, aplikasi smart training mudah } \\
\text { digunakan. }\end{array}$ & 1 & 2 & 3 & 4 & 5 \\
\hline 2 & Fungsi-fungsi sudah sesuai dengan yang diharapkan. & 1 & 2 & 3 & 4 & 5 \\
\hline 3 & $\begin{array}{l}\text { Antar muka aplikasi mudah dipahami, menarik, dan dipakai } \\
\text { tanpa kesulitan }\end{array}$ & 1 & 2 & 3 & 4 & 5 \\
\hline 4 & $\begin{array}{l}\text { Aplikasi smart training mempermudah penyampaian } \\
\text { materi dan penilaian training }\end{array}$ & 1 & 2 & 3 & 4 & 5 \\
\hline
\end{tabular}

Luthfyana, et., al [Rancang Bangun Aplikasi Smart Training Berbasis Android Menggunakan Flutter Dengan Metode RAD] 


\begin{tabular}{|c|l|c|c|c|c|c|}
\hline 5 & $\begin{array}{l}\text { Aplikasi smart training mengurangi penggunaan kertas } \\
\text { yang selama ini digunakan untuk menyelenggarakan } \\
\text { training }\end{array}$ & 1 & 2 & 3 & 4 \\
\hline 6 & $\begin{array}{l}\text { Aplikasi yang dibuat tidak terasa berat saat dijalankan di } \\
\text { perangkat Android. }\end{array}$ & 1 & 2 & 3 & 4 & 5 \\
\hline 7 & $\begin{array}{l}\text { Fitur smart media sangat membantu untuk meningkatkan } \\
\text { minat baca pengguna aplikasi }\end{array}$ & 1 & 2 & 3 & 4 & 5 \\
\hline 8 & $\begin{array}{l}\text { Aplikasi smart training menjadi salah satu solusi yang baik } \\
\text { dalam penerapan protocol Kesehatan di waktu pandemic } \\
\text { virus Covid-19 }\end{array}$ & 2 & 3 & 4 & 5 \\
\hline
\end{tabular}

Kuesioner dilakukan setelah melakukan sosialisasi dan penyebaran aplikasi. Responden dari kuesioner usability testing adalah 11 user office yang merupakan peserta training di PT. PB Unit PST. Hasil kuesioner diperlihatkan pada Grafik 1.

HASIL KUESIONER SYSTEM USABILITY

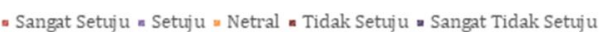

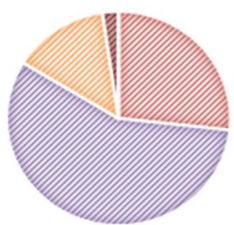

Gambar 19. Grafik Hasil Kuesioner System Usability

Berdasarkan hasil dari kuesioner, kemudian dilakukan perhitungan hasil dengan Skala Likert.Skala Likert adalah skala yang digunakan untuk mengukur persepsi, pendapat seseorang atau kelompok, dalam hal ini konteksnya adalah sistem smart training yang sudah dibuat [13]. Perhitungan menggunakan bobot nilai Skala Likert dapat dilihat pada Tabel 3 dan hasilnya pada Tabel 4.

Tabel 3. Bobot Nilai Skala Likert

\begin{tabular}{|l|c|}
\hline \multicolumn{1}{|c|}{ Jawaban } & Bobot Nilai \\
\hline SS (Sangat Setuju) & 5 \\
\hline S (Setuju) & 4 \\
\hline N (Netral) & 3 \\
\hline TS (Tidak Setuju) & 2 \\
\hline STS (Sangat Tidak Setuju) & 1 \\
\hline
\end{tabular}

Tabel 4. Perhitungan Hasil Kuesioner Menggunakan Bobot Nilai Skala Likert

\begin{tabular}{|l|c|c|}
\hline \multicolumn{1}{|c|}{ Jawaban } & Jumlah & Total Nilai \\
\hline SS (Sangat Setuju) & 24 & 120 \\
\hline S (Setuju) & 49 & 196 \\
\hline N (Netral) & 12 & 36 \\
\hline TS (Tidak Setuju) & 2 & 4 \\
\hline STS (Sangat Tidak Setuju) & 0 & 0 \\
\hline & Total & 356 \\
\hline
\end{tabular}


Hasil akhir dari skala Likert dihitung dengan cara mengalikan jumlah setiap kategori jawaban dengan bobot nilainya [13]. Total nilai didapatkan dengan menjumlahkan hasil perkalian sebelumnya. Pada Tabel 4 didapatkan hasil akhir nilai dari kuesioner yang dilakukan adalah 356. Kemudian untuk mengetahui persentase kepuasan mengenai sistem yang dibuat digunakan rumus \% Kepuasan. \% Kepuasan dihitung dengan cara sebagai berikut:

$$
\begin{gathered}
\mathrm{Y}=5 \times \mathrm{p} \times \mathrm{q}(1) \\
\% \text { Kepuasan }=\frac{\text { total nilai }}{Y} \times 100
\end{gathered}
$$

Keterangan:

- Y adalah hasil akhir perkalian antara p, q, dan 5

- p adalah total responden

- $\mathrm{q}$ adalah total pertanyaan yang diberikan kepada responden

$$
\begin{aligned}
\mathrm{Y} & =5 \times 11 \times 8(3) \\
& =440 \therefore
\end{aligned}
$$

Berdasarkan hasil perhitungan $\mathrm{Y}$ diatas didapatkan hasil sebesar 440, kemudian hasil ini akan di gunakan untuk menghitung \% Kepuasan dengan rumus sebagai berikut:

$$
\begin{aligned}
\% \text { Kepuasan } & =\frac{\text { total nilai }}{Y^{\prime}} \times 100(4) \\
& =\frac{356}{440} \times 100 \\
& =80,90 \% \therefore
\end{aligned}
$$

Perhitungan keputusan kemudian dilakukan dengan mencocokan hasil yang didapat dengan rumus \% Kepuasan dengan tabel persentase pada Skala Likert. Tabel 5 menunjukan tabel persentase yang digunakan untuk mengkategorikan skala kepuasan berdasarkan nilai yang didapat

Tabel 5. Persentase Kategori Nilai Skala Likert [13]

\begin{tabular}{|c|c|}
\hline$\%$ Kepuasan & Keterangan \\
\hline $0 \%-19.99 \%$ & Sangat Buruk \\
\hline $20 \%-39.99 \%$ & Kurang Baik \\
\hline $40 \%-59.99 \%$ & Cukup \\
\hline $60 \%-79.99 \%$ & Baik \\
\hline $80 \%-100 \%$ & Sangat Baik \\
\hline
\end{tabular}

Berdasarkan semua perhitungan dengan Skala Likert didapatkan kesimpulan bahwa sistem yang dibuat sudah memenuhi keinginan dari responden dan rumusan masalah dari penelitian ini. Kesimpulan ini diambil dari nilai \% Kepuasan yang mencapai $80.91 \%$ dan dicocokan menggunakan nilai persentase pada Tabel 5 yang mengkategorikan nilai yang didapat dalam kategori sangat baik [11].

\section{KESIMPULAN}

Berdasarkan penelitian yang dilakukan, didapat kesimpulan yaitu untuk membuat sebuah sistem smart training yang dapat diakses oleh PT. PB Unit PST secara langsung adalah dengan membuat sistem yang diimplementasikan ke dalam Aplikasi berbasis Android serta Headless CMS. Aplikasi Android ini adalah aplikasi yang dipakai oleh user untuk mengakses konten dan mengikuti berbagai rangkaian training yang disediakan, sedangkan website admin yang berbasis Headless CMS dipakai untuk mengelola konten di dalam aplikasi user serta mengaktifkan akun user. Sistem smart training yang dibuat pada penelitian ini dapat memberikan laporan data training yang sudah dilakukan, data tersebut berisikan nama, tanggal training, hasil pre test dan

Luthfyana, et., al [Rancang Bangun Aplikasi Smart Training Berbasis Android Menggunakan Flutter Dengan 
post test serta feedback yang diberikan oleh user untuk training yang sudah berlangsung, data ini dapat diakses dengan memasukkan alamat domain yang sudah dibuat dan data akan otomatis di download dalam format CSV(Comma Separated Value). Prototype sistem smart training dalam penelitian ini juga dapat digunakan untuk menggantikan sistem training lama yang dinilai kurang efisien. Beberapa hal yang dipertimbangkan untuk menggunakan sistem baru adalah adanya fitur Firebase Cloud Messaging yang tidak mengharuskan karyawan divisi training melakukan panggilan telepon kepada karyawan yang harus mengikuti training, admin hanya perlu menginputkan training untuk user tersebut dan sistem akan mengirimkan notifikasi ke dalam aplikasi user. Selain itu sistem smart training yang telah dibuat juga memiliki fitur pre test, post test, pengisian feedback serta pengisian polling secara online, fitur ini akan sangat membantu perusahaan untuk menekan biaya operasional untuk pembelian kertas serta dapat mengurangi penggunaan kertas. Aplikasi ini juga memiliki \%Kepuasan sebesar 80,91\% dan dikategorikan sangat baik.

\section{SARAN}

Untuk penelitian selanjutnya sebaiknya berfokus pada pengembangan aplikasi untuk di platform lain dan pengembangan fitur-fitur yang menarik lainnya agar user tertarik untuk menggunakan aplikasi ini. Pengembang aplikasi menyarankan perusahaan untuk melakukan maintenance setiap minggunya untuk menjaga perfoma dari aplikasi smart training ini.

\section{UCAPAN TERIMA KASIH}

Penulis mengucapkan terima kasih kepada Tuhan Yang Maha Esa, ibu yang sudah mendukung penulis dari awal hingga akhir, serta Dhemas E. Rilian Nurjaya yang sudah mensupport penulis dan membimbing penulis hingga aplikasi berjalan dengan baik.

\section{DAFTAR PUSTAKA}

[1] Pura Group. 2020, https://www.puragroup.com/en/about-us/ (Accsessed Jan. 4 2021).

[2] Noertjahyana, A. 2002, "Studi Analisis Rapid Aplication Development Sebagai Salah Satu Alternatif Metode Pengembangan Perangkat Lunak", https://jurnalinformatika.petra.ac.id, (Accsessed Mei. 11 2021)

[3] Vogel, L, Hungershausen, J. 2021, "Whats is The Flutter Applications Framework”, https://www.vogella.com/tutorials/Flutter/article.html\#flutter (Accsessed Mar. 16 2021).

[4] S. O’Dea. 2021, https://www.statista.com/statistics/272698/global-market-share-held-bymobile-operating-systems-since-2009/ (Accsessed Mar. 20 2021).

[5] Sharma, N. 2021," What Is Strapi and Why You Should Use It", https://javascript.plainenglish.io/what-is-strapi-and-why-you-should-use-it-ce4e653f5c6e (Accsessed Mar. 20 2021). 
[6] Roybal, K. 2020, "PostgreSQL Is The Worlds' Best Database", https://www.2ndquadrant.com/en/blog/postgresql-is-the-worlds-best-database/ (Accsessed Jan. 4 2021).

[7] Hakim, AR., and Harefa, K., and Widodo, B. 2019, Pengembangan Sistem Informasi Akademik Berbasis Android Menggunakan Flutter di Politeknik, Scan Vol. XIV Nomor 3.

[8] Firmansyah, D. 2019, Pengembangan Front-End Aplikasi Mobile E-Recruitment Menggunakan Flutter, Universitas Islam Indonesia.

[9] Bitlabs Academy 2019, ”Apa itu RAD? Mengenal Salah Satu Metode Pengembangan Aplikasi,” https://bitlabs.id/blog/rad-adalah/ (Accsessed Jan. 22 2021).

[10] Hasibuan, Zainal A. 2007, "Metodologi Penelitian pada Bidang Ilmu Komputer dan Teknologi Informasi,” Depok.

[11] Dumas, J. S. 1999, A Practical Guide to Usability Testing, Intellect Books.

[12] Lewis, J. R. 1995, IBM Computer Usability Satisfaction Questionnaires: Psychometric Evaluation and Instructions for Use, International Journal of Human Computer Interaction, 7(1), 57-78.

[13] Editor, Choizes. 2017, "Pengertian Skala Likert dan Contoh Cara Hitung Kuesionernya”, https://www.diedit.com/skala-likert/ (Accsessed Feb. 27 2021). 